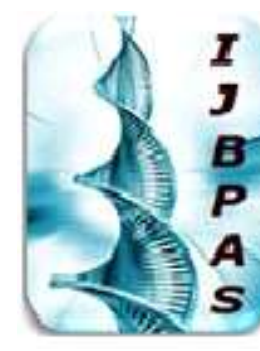

International Journal of Biology, Pharmacy and Allied Seiences (IJBPAS)

'A Bridge Betusen Caboratory and Qnendo'

WwW.ijbpas.com

\title{
FACTORS INFLUENCING ONLINE CONSUMER PURCHASE INTENTION
}

\section{KAIWALYA JOSHI*, SAURABH K, AMIT MEENA AND SNEHA DAS}

Symbiosis Institute of Business Management Pune, Symbiosis International (Deemed

University), Pune, India

*Corresponding Author: E Mail: kaiwalya.joshi.mba22@associates.sibmpune.edu.in

Received 19 ${ }^{\text {th }}$ May 2021; Revised $4^{\text {th }}$ June 2021; Accepted $9^{\text {th }}$ July 2021; Available online $25^{\text {th }}$ Sept. 2021

https://doi.org/10.31032/IJBPAS/2021/10.9.1006

\begin{abstract}
This paper explores the conceptual model that comprehensively describes the essential elements of online shopping experience. In this research, an extensive survey of existing related studies was made and their findings were amalgamated into a model called OSE (Online Shopping Experience Model). The factors that have been examined in previous studies were classified based on their similarity and pattern of their findings. This resulted in the conclusion that numerous factors have been examined in the online shopping context and diverse results on those factors have been reported. The proposed model in this study helps to ascertain the factors that influences online shopping experience which is wide open for future research avenues.
\end{abstract}

Keywords: Online marketing, online shopping, online shopping experience, Customer online shopping, India

\section{INTRODUCTION}

In recent years, online shopping is becoming more predominant by offering several benefits to the consumers. Online shopping is becoming progressively more popular and is attracting a great attention due to its potential for both customers and e-vendors which stimulates the widespread research aim in online shopping arena. Despite the fact that interactive nature of online shopping offers 
many opportunities, online practitioners need to develop a broad understanding of consumer in online environment. Although several researchers have attempted to resolve this issue, only few studies have examined the factors influencing the online shopping experience exclusively [1]. Several studies says that, experience is the strongest generator of self-efficacy and thus generating positive experience has acquired greater prominence due to its potentiality in influencing customer loyalty [1]. Online consumer experiences refer to the psychological and emotional states that consumers go through while shopping in online platform. Clear understanding of online shoppers is vital for online stores to make effective business strategies involving technology, marketing, and Web site design [3]. Especially, understanding customer experience adds the ability to predict their future behaviour because prior shopping experience plays a major role in stimulating online buying intentions of the consumers [4].

Further, the growing interest in exploring what factors affect consumers decisions to make purchases online was stimulated by the tremendous growth in online sales [5]. In addition, as the success of retail store depends on delivering an effective customer experience [6], it is important to provide effective experiential measures to the customer in online platform. Consequently, the aim of this paper is to develop a general model of the online customer experience based on existing literatures. This paper would assist comprehensive understanding of consumer needs in online shopping. Furthermore, analyzing previous studies and recognizing the areas that needs enhancement could contribute to the betterment of e-business practitioners.

\section{REVIEW OF LITERATURE}

Experience research typically focuses on the requirement to go beyond the usability in overall system design and evaluation. Mosteller, Donthu and Eroglu, (2014) spots the importance of online experience by suggesting that further investigation is needed to examine the effect of key factors on online shopping experience.

The growing stream of literature devoted to e-services denotes the importance of the medium. For instance, Parasuraman et al., (1991), developed the e-SERVQUAL scale comprised of four key sub-scales: efficiency, reliability, fulfilment, and privacy. Kaynama and 
Black (2000), have explored seven features pertaining to Web site quality: content, access, navigation, design, response, background, and personalization. Another study outlines performance, access, security, sensation, and information as five aspects used by consumers to assess the quality of an online retailer. Tong (2010), have added certain other dimensions such as ease of use, aesthetic design, processing speed, and security. However, the roles of other types of online customer experiences have not received sufficient attention in academic marketing literature. This knowledge gap presents an important research opportunity which emphasises experience-based differentiation as a major online strategy for sustainable competitive advantage. While abundant marketing literature focuses on customer satisfaction and service quality online, only few researches has analysed the relative importance of various shopping experience components. This study would provide several contributions to the emarketing and retailing literature that both brings new knowledge and extends existing knowledge, by developing a clear understanding of what contributes online shopping experience. Based on the existing literature, individual factors influencing online shopping experience and their impact on intention to repurchase has been ascertained. In particular, five main types of consumer factors such as motivation, convenience, service quality, website and accessibility has been identified. This paper provides a better understanding based on the mixed findings across different studies.

\section{Motivation}

Several studies have examined the facet of motivation with respect to online shopping environments (Novak et al., 2000). For instance, motivation is a most constructive aspect that supports the investigation of customer engagement (Mehta, Sharma and Swamy, 2013). In particular, Hill, Beatty and Walsh (2013) have found that shopping motivations consist of three various dimensions such as wish to obtain a product, desire to satisfy needs, and goal of accomplishing certain ends. A recent study found that motivation was stressing at the point of to having an experience like fun or socializing with others that ultimately helps in discovering why people goes for online shopping.

As customer experience is associated with pleasure, arousal, and achieving a specific end while shopping, it is more often compared with the terms "hedonic" and "utilitarian" in several studies. 
According to Handa and Gupta (2014), hedonic classifications are related to intrinsically motivated intentions, while utilitarian classifications are related to extrinsic motivational aspects. As such, pleasurable motivations bring individuals to the interface by influencing their experiences and keep them involved in the interaction emotionally.

\section{Therefore it is proposed that motivation} influences the online shopping experience.

\section{Convenience}

Numerous shopping studies have identified convenience as a discrete drive for online store choice (Jiang, Yang and Jun, 2013; Liu \& Forsythe, 2010). Convenience shoppers are often characterized as selecting things based on time or effort savings. Consumers acquire greater experience in online shopping because it reduces the burden of visiting the store in person (Park et al., 2013). As location becomes irrelevant when it comes to online shopping, customers acquires the opportunity to shop at home anytime and anywhere.

Another major benefit in online shopping is that customers are more convenient in collecting the product information and finding valuable alternatives [11]. This provides the better experience since it reduces the search costs particularly when the customer is under time pressure. Thus, convenience includes the elements of when and where consumers can shop. In this perspective of convenience, customers are more likely to gain the

new mixed experience of "usefulness" and "ease of use." In other words, decreased frustration will make the shopping experience more enjoyable.

$P_{2}$. Therefore it is proposed that convenience influences the online shopping experience.

\section{Service Quality}

The service quality is the ultimate measure resulted from comparing the expectations and performance. Parasuraman et al., (1991) has developed the SERQUAL scale that gives a wholesome view over service quality comprising five dimensions such as tangibility, empathy, reliability, responsiveness, and assurance. Service quality plays a significant role in boosting up the customer experience. Due to the rapid increase in the progress, consumers become more occupied by the emarketplace.

Since the growth of the online shopping would depend on improvement in 
service quality, it is important to evaluate and promote consumer preferences by offering things for which the customer shopping experience is similar to traditional store outlets [12]. Though online shopping is enjoyed more by young consumers, the occurrence of rapid growth in this industry is also persuaded by older shoppers because of its efficiency in servicing technologies.

$P_{3}$. Therefore it is proposed that service quality influences the online shopping experience.

\section{Website}

Websites that go well together with the Indian culture were exposed to be more positively perceived by the customers [13]. Moreover it influences the purchase intention and attitude toward the site. Reliability, customer service, privacy and security are identified as the most common dimensions of website design. Numerous studies has studied that website quality as a positive influencer of consumer online purchase intention. Website design plays a major role in attracting the large customer base. In addition, previous findings have proven that consumers who are familiar with websites will build a high intention to purchase online. Consumers will always tend to visit user-friendly websites and in contrast, if they feel that a webite is hard to use and to follow, they will show a lower intention to purchase in online (Thamizhvanan and Xavier, 2013).

$P_{4}$. Therefore it is proposed that website influences the online shopping experience.

\section{Accessibility}

In online shopping context, accessibility plays a vital role since consumers prefer the medium that demonstrates an accessible user interface (Overmars \& Poels, 2015). In recent years, people often consider buying things from online if they feel hard in fighting crowds or finding that their product is no longer available

in retail stores because of the ease of accessibility in online shopping [15]. Here, consumers have more advantageous benefits in terms of searching through filtering product category, price, color, size, etc.

While shopping in online, consumers expects and prefers the site that has no accessibility violations. As many online retailers provide accessible technologies like voice recognition software, screen reader, magnifier, etc. physically challenged people finds it easy to shop online [14]. Increased standards of 
accessibility makes the customer online shopping experiences the best they can be. accessibility influences the online shopping experience.

\section{$P_{5}$. Therefore it is proposed that}

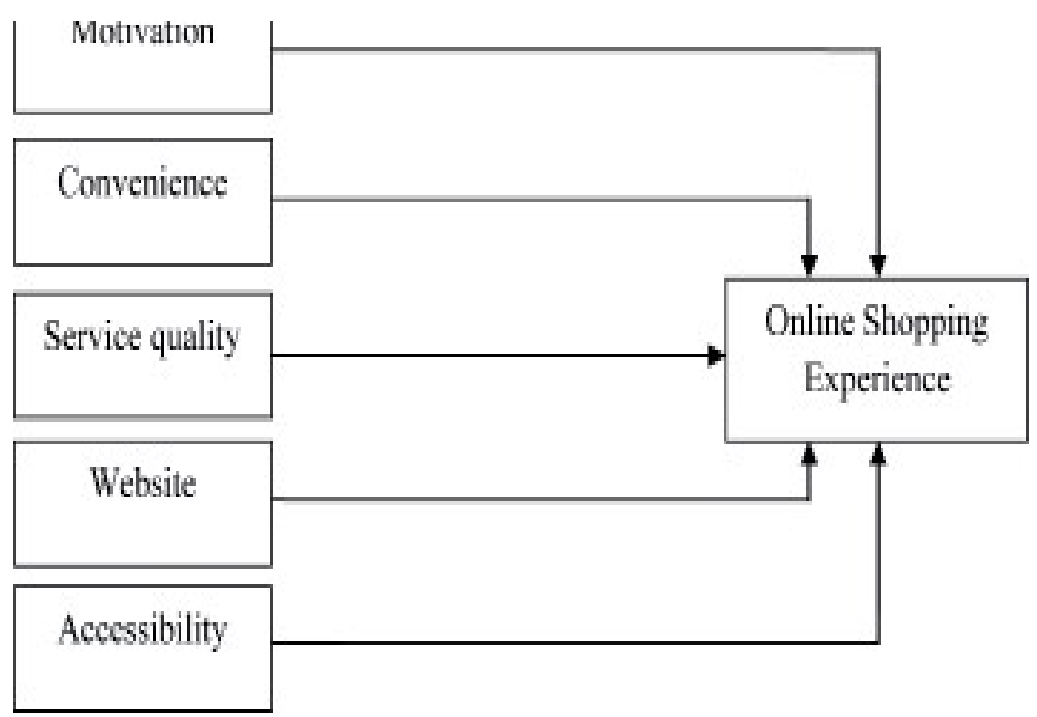

Figure 1: Conceptual Framework

\section{RESEARCH IMPLICATION AND FUTURE RESEARCH DIRECTIONS}

The proposed conceptual model in this paper suggest a number of research avenues. As this study associates online shopping with experiential aspects, there are numerous opportunities for theoretical and empirical research in this area. The links proposed in the model offers several ways for a detailed assessment of specific relationships and their outcomes.

The first step towards theory building involves furnishing customer engagement. There is a need to keep the customers involved emotionally by acknowledging fun and pleasure. While the suggested measure of motivation may be appropriate, more detailed research is needed in this venue. Further, additional research could be undertaken to identify whether there is an effect of unidentified elements on store choice. The proposed model suggests convenience as the most important variable that influences the customer online shopping experience. Yet, there is a potentiality for other factors, such as involvement and confidence, which may be applicable in this context.

In addition, variables produced by the internet research is more applicable to the online shopping experience that are offered by the technology. One such variable is service quality, which describes the extent to 
which consumers exaggerates in virtual marketplace. As suggested, service quality influences the level of online shopping experience, an empirical evidence is required to reveal if this is the case. A case in point is the work of website dimension which has been successfully applied to the online shopping context. Several researches has been done on analyzing website dimension in online shopping context. However, future studies could examine the applicability of website dimension in tuning online shopping experience through an empirical research. Finally, it is suggested that accessibility is the factor that triggers the customer online shopping experience to a great extent. The proper analysis of this aspect can enhance the understanding of how online shopping experience is affected by the online shopping environment. This issue has a great bearing on the potency of atmospheric qualities that represent the online shopping store. Much creative research can be formulated on the nature and impact of this suggested model. From a technical perspective, research on online shopping is booming up and sets a whole new set of research avenues. Specifically, empirical research on the experiential aspects of online shopping needs much attention due to the physical and practical constrictions.

\section{CONCLUSION}

The objective of this research was to explore the components of consumer experience while shopping online. An extensive review of literature across major fields on online shopping has been conducted to identify the varied aspects and concepts of shopping experiences. An integrative conceptual framework of online shopping experience has been propsed based on the review of literature. This framework adds knowledge and understanding of consumers while shopping online.

In conclusion, this research is likely to receive increasing academic and managerial attention. Apparently, the research area is wide open to all kinds of theoretical and methodological contributions. In particular, it affords the marketing researchers the unique opportunity to permeate the regulation with new paradigms and techniques.

\section{REFERENCES}

[1] Alba, Joseph W. and J. Wesley Hutchinson. Knowledge Calibration: What Consumer Know and What They Think They Know. Journal of Consumer Research, Volume 27. September 2000, pg. 123.

[2] Duan, W., Gu, B., \&Whinston, A. B. (2008). Do online reviews matter?An empirical investigation of panel data. Decision support systems, 45(4), 
1007-1016.

[3] Handa, M., \& Gupta, N. (2014). A study of the relationship between shopping orientation and online shopping behavior among Indian youth. Journal of Internet Commerce, 13(1), $22-44$

[4] Hartono, E., Holsapple, C. W., Kim, K. Y., Na, K. S., \& Simpson, J. T. (2014).

[5] Measuring perceived security in B2C electronic commerce website usage: A respecification and validation.

Decision Support Systems, 62, 11-21.

[6] Hill, W. W., Beatty, S. E., \& Walsh, G. (2013). A segmentation of adolescent online users and shoppers. Journal of Services Marketing, 27(5), 347-360.

[7] Jiang, L., Yang, Z., \& Jun, M. (2013). Measuring consumer perceptions of online shopping convenience. Journal of Service Management, 24(2), 191-214.

[8] Kaynama, S. A., \& Black, C. I. (2000). A proposal to assess the service quality of online travel agencies: An exploratory study. Journal of professional services marketing, 21(1), $63-88$

[9] Khare, A., Khare, A., \& Singh, S. (2012). Attracting shoppers to shop online-Challenges and opportunities for the Indian retail sector. Journal of Internet Commerce, 11(2), 161-185.

[10] Khare, A., \& Rakesh, S. (2011).
Antecedents of online

shopping behavior in India: An examination. Journal of Internet Commerce, 10(4), 227-244.

[11] Ling, K. C., Chai, L. T., \&Piew, T. H. (2010). The effects of shopping orientations, online trust and prior online purchase experience toward customers' online purchase intention. International Business Research, 3(3), 63.

[12] Liu, C., \& Forsythe, S. (2010). Postadoption online shopping continuance. International Journal of Retail \& Distribution Management, 38(2), 97-114.

[13] Mehta, R., K. Sharma, N., \& Swami, S. (2013). A typology of Indian hypermarket shoppers based on shopping motivation. International Journal of Retail \& Distribution Management, 42(1), 4055.

[14] Mosteller, J., Donthu, N., \& Eroglu, S. (2014). The fluent online shopping experience. Journal of Business Research, 67(11), 2486-2493.

[15] Nambisan, P., \& Watt, J. H. (2011). Managing customer experiences in online product communities. Journal of Business Research, 64(8), 889-895.

[16] Novak, T. P., Hoffman, D. L., \& Yung, Y. F. (2000). Measuring the Customer Experience in Online environments: A 
Structural modeling approach.

Marketing Science 19(1), 22-42.

[17] Overmars, S., \& Poels, K. (2015). Online product experiences: The effect of simulating stroking gestures on product understanding and the critical role of user control. Computers in Human Behavior, 51, 272-284.

[18] Pahnila, S., \&Warsta, J. (2010). Online shopping viewed from a habit and value perspective. Behaviour\& Information Technology, 29(6), 621632.

[19] Parasuraman, A., Berry, L. L., \& Zeithaml, V. A. (1991). Refinement and reassessment of the SERVQUAL scale. Journal of retailing, 67(4), 420.

[20] Park, S. B., Lee, Y. K., \& Chung, N. (2013). Why don't consumers go internet shopping in Korea? Segmentation of consumer lifestyle approach. Behaviour\& Information Technology, 32(5), 468-479.

[21] Rose, S., Clark, M., Samouel, P., \& Hair, N. (2012). Online customer experience in e-retailing: an empirical model of antecedents and outcomes. Journal of Retailing, 88(2), 308-322.

[22] Rose, S., Hair, N., \& Clark, M. (2011). Online customer experience: A review of the business-to- consumer online purchase context. International Journal of Management Reviews, 13(1), 24-39.
[23] Thamizhvanan, A., \& Xavier, M. J. (2013). Determinants of customers' online purchase intention: an empirical study in India. Journal of Indian Business Research, 5(1), 17-32.

[24] Tong, X. (2010). A cross-national investigation of an extended technology acceptance model in the online shopping context. International Journal of Retail \& Distribution Management, 38(10), 742-759.

[25] Tsao, W. C., \& Tseng, Y. L. (2011). The impact of electronic-service quality on online shopping behaviour. Total Quality Management \& Business Excellence, 22(9), 1007-1024. 